\title{
Effect of stirring on striae in glass melts
}

\author{
Jensen, Martin; Yue, Yuanzheng
}

Published in:

Journal of Non-Crystalline Solids

DOI (link to publication from Publisher):

10.1016/j.jnoncrysol.2011.09.040

Publication date:

2012

\section{Document Version}

Early version, also known as pre-print

Link to publication from Aalborg University

Citation for published version (APA):

Jensen, M., \& Yue, Y. (2012). Effect of stirring on striae in glass melts. Journal of Non-Crystalline Solids, 358(2), 349-353. https://doi.org/10.1016/j.jnoncrysol.2011.09.040

\section{General rights}

Copyright and moral rights for the publications made accessible in the public portal are retained by the authors and/or other copyright owners and it is a condition of accessing publications that users recognise and abide by the legal requirements associated with these rights.

- Users may download and print one copy of any publication from the public portal for the purpose of private study or research.

- You may not further distribute the material or use it for any profit-making activity or commercial gain

- You may freely distribute the URL identifying the publication in the public portal -

\section{Take down policy}

If you believe that this document breaches copyright please contact us at vbn@aub.aau.dk providing details, and we will remove access to the work immediately and investigate your claim. 
Provided for non-commercial research and education use. Not for reproduction, distribution or commercial use.

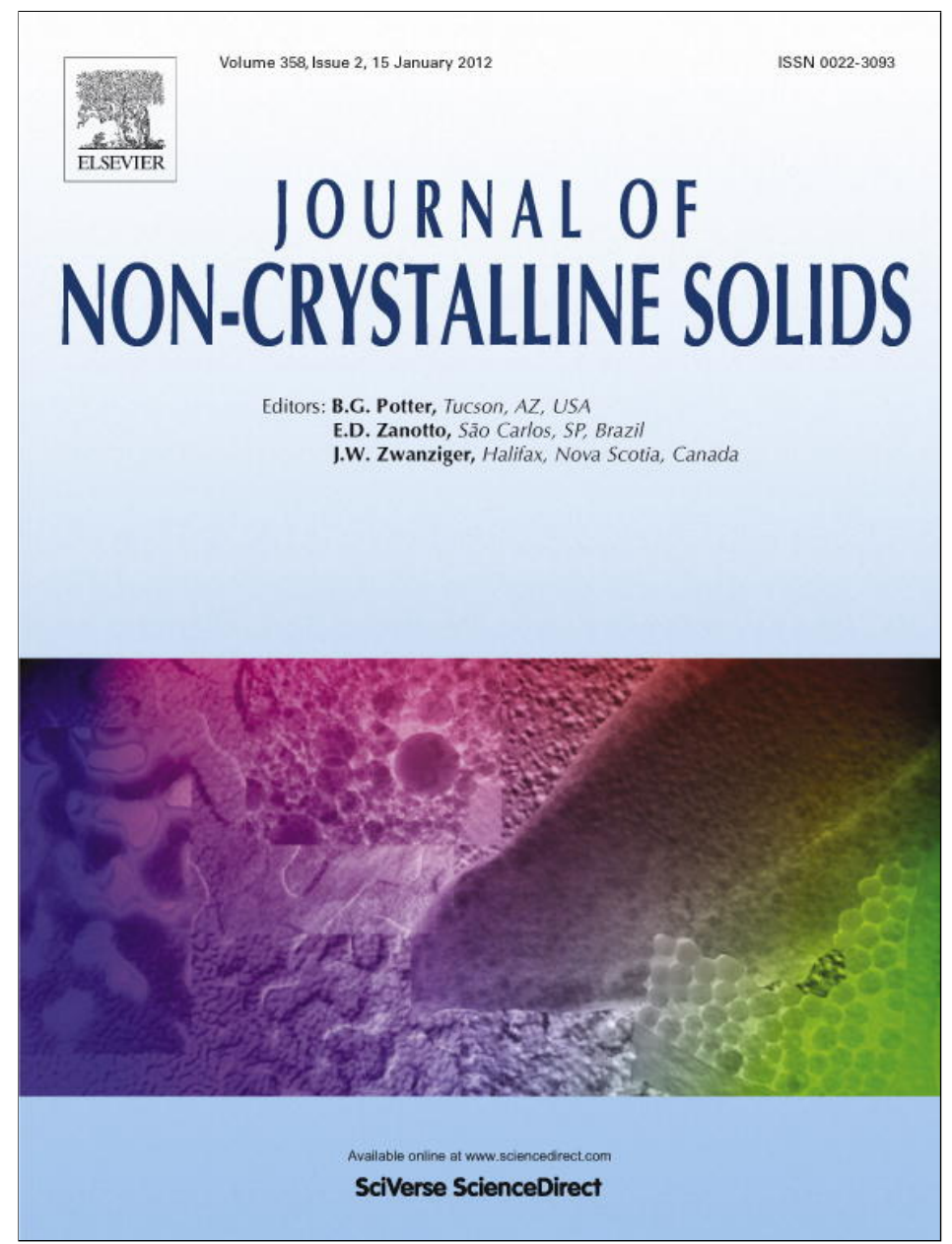

This article appeared in a journal published by Elsevier. The attached copy is furnished to the author for internal non-commercial research and education use, including for instruction at the authors institution and sharing with colleagues.

Other uses, including reproduction and distribution, or selling or licensing copies, or posting to personal, institutional or third party websites are prohibited.

In most cases authors are permitted to post their version of the article (e.g. in Word or Tex form) to their personal website or institutional repository. Authors requiring further information regarding Elsevier's archiving and manuscript policies are encouraged to visit:

http://www.elsevier.com/copyright 


\title{
Effect of stirring on striae in glass melts
}

\author{
Martin Jensen, Yuanzheng Yue* \\ Section of Chemistry, Aalborg University, 9000 Aalborg, Denmark
}

\section{A R T I C L E I N F O}

\section{Article history:}

Received 1 August 2011

Received in revised form 27 September 2011

Available online 26 October 2011

\section{Keywords:}

Melt homogenization;

Stria;

Stirring;

Retention;

Diffusion

\begin{abstract}
A B S T R A C T
Chemical striae have often negative effect on the glass properties, and hence, elimination of striae has been a key issue in glass science and technology. To produce highly homogeneous glasses, it is necessary to stir melts during the melting process. To explore the physical origin of the stria elimination during stirring, and to optimise the homogenisation process, both simulations of striation and homogenisation experiments are performed. The results show that stirring broadens the stria size distribution in the melt through conversion of larger striae into smaller ones. Only the striae with a size below half the diffusion length in the melt can be eliminated during the melting process. Stirring itself does not homogenise the melt, but enhances the stria elimination rate by generating small striae.
\end{abstract}

(c) 2011 Elsevier B.V. All rights reserved.

\section{Introduction}

The homogeneity of glasses is important to their physical properties [1,2], and hence, homogenisation of the melt is a crucial step in glass production. Inhomogeneitiy is a complex term since it is influenced and determined by several factors such as bubbles and striae. Some types of striae are of physical origin, i.e., difference in cooling rate, while others are of chemical origin, i.e., difference in the chemical composition and/or redox state. As a stria is a three dimensional amorphous domain within the glass matrix, the stria can be described by different parameters such as its volume (size), geometry and compositional difference. Due to the strong impact of inhomogeneities on glass performance, glass scientists and technologist have made considerable efforts in finding ways to characterise, understand and remove inhomogeneities from glass products [3-13]. Often the extent of striations in a glass melt is reduced by elevating the melting temperature and/or prolonging the retention time. Until the research of optical glasses began in Jena more than one century ago, glass technologists did not realise that application of a high temperature resistant stirrer during melting process is one of the most efficient techniques to achieve high homogeneity of a glass melt. Since then, studies have been conducted to elucidate the effect of stirring on the homogeneity of glass melts [14-18]. Most of those studies focus on the major source of inhomogeneity, namely, stria, which is also the object of the present study. Despite progress of earlier studies in improving the homogenisation process by stirring and in understanding its mechanism, some key questions are still not fully understood. What is the physical origin of the homogenisation enhancement by stirring? Is stirring during the entire

\footnotetext{
* Corresponding author. Tel.: + 45 99408522; fax: + 4596350558. E-mail address: yy@bio.aau.dk (Y.Z. Yue).
}

melting process desirable or does a threshold for the homogeneity improvement by stirring exist? What are the individual roles of retention and stirring on the elimination of striae from glass melts?

To clarify those questions, we have designed and performed a simple set of stirring-retention combined experiments on a borosilicate model glass melt. Furthermore, through image processing we simulate the evolvement of striae, and directly reveal the influence of stirring on the stria size and the compositional difference to the glass matrix.

\section{Experimental}

\subsection{Modelling}

An image of a periodic striation with a stria length of 200 pixels was generated using the programme Gimp (GNU image manipulation programme). The stria was introduced by the blend function with a $0-255$ linear grey scale gradient and a triangular wave repetition. As a grey value of 0 and 255 corresponds to completely black and white, respectively the colour of the simulated stria changes between black and white. The grey scale gradient was started at 0,0 pixel and ended at the position 50,50 pixel. The reasons for choosing a triangular wave are described in detail elsewhere [19]. The striation was subjected to 1,2 or 3 stirrings of $360^{\circ}$ by applying the whirl function in Gimp. For the stirring, a pinch amount of 0.5 and a radius of 1.3 were used.

\subsection{Glass melting}

Borosilicate glass with the composition (wt.\%): $49.7 \mathrm{SiO}_{2}, 20.5 \mathrm{~B}_{2} \mathrm{O}_{3}$, $2.0 \mathrm{Al}_{2} \mathrm{O}_{3}, 4.0 \mathrm{Li}_{2} \mathrm{O}, 7.8 \mathrm{Na}_{2} \mathrm{O}, 4.0 \mathrm{~K}_{2} \mathrm{O}, 3.0 \mathrm{CaO}, 9.0 \mathrm{ZnO}$ was prepared and used for the homogenisation experiments. In addition, another glass with the same basic composition, but containing $0.4 \mathrm{wt} . \% \mathrm{CoO}$ was produced. The addition of $\mathrm{COO}$ to the batch causes intense blue colouring of 
the glass. After casting of the $\mathrm{CoO}$ doped borosilicate glass, it was crushed and the pieces with size of 1-2 mm were collected for further melting experiments.

$150 \mathrm{~g}$ of the borosilicate glass melt were produced in a $\mathrm{Pt}_{90} \mathrm{Rh}_{10}$ crucible (diameter $7.3 \mathrm{~cm}$, height $8 \mathrm{~cm}$ ) in an induction furnace equipped with a $40 \mathrm{~kW}$ generator (Hüttinger, Germany). The batch was initially melted at $1120^{\circ} \mathrm{C}$ for $1 \mathrm{~h}$ to obtain a homogeneous glass melt. At $1120^{\circ} \mathrm{C}$, the viscosity of the melt was measured by means of rotational viscometry, and was found to be $1.7 \mathrm{~Pa} \cdot \mathrm{s}$. The viscosity was measured using a concentric cylinder viscometer under atmospheric conditions. The furnace was a box furnace (model HT 7, Scandiaovnen A/S, Allerød, Denmark) and the viscometer head was a Physica Rheolab MC1 (Paar Physica, Stuttgart, Germany). During the melting process, the platinum crucible was covered with an alumina lid to maintain a uniform temperature in the entire melt. After $1 \mathrm{~h}$ at $1120^{\circ} \mathrm{C}$, the alumina lid was removed and $0.75 \mathrm{~g} \mathrm{CoO}$ doped glass grains with a size of $1-2 \mathrm{~mm}$, were added to the $150 \mathrm{~g}$ glass melt. Afterwards, the glass grains were dissolved into the original clear glass melt in the crucible under the alumina lid for $2 \mathrm{~min}$. After the $\mathrm{CoO}$ doped glass pieces were melted, a 15 min homogenisation process including a certain duration of stirring was initiated. Two series of homogenisation experiments were performed. For the first series, the melt underwent a period of stirring and subsequently a period of retention (denoted as the SR series) (see Table 1). For the second series, the opposite is the case, i.e., the melt first underwent a period of retention and subsequently a period of stirring (denoted as the RS series). For each melt sample in the SR and RS series a new batch of $150 \mathrm{~g}$ was prepared. The durations of retention and stirring in the SR and RS series are given in Table 1. During both the retention and the stirring period, the crucible was covered with an alumina lid. For the stirring periods the crucible was covered by an alumina lid with a hole for the stirrer. To stir the melt, a $\mathrm{Pt}_{90} \mathrm{Rh}_{10}$ stirrer with a propeller (height $2 \mathrm{~cm}$ and total width $4 \mathrm{~cm}$ ) was used. The speed of the stirring was fixed at 20 rounds $/ \mathrm{min}$. After the $15 \mathrm{~min}$ homogenisation interval, the melt was kept at $1120^{\circ} \mathrm{C}$ for another $5 \mathrm{~min}$ before casting

The melt was cast in a mould with a brass bottom and steel walls and was allowed to cool for $\sim 10 \mathrm{~s}$. Then the glass piece was transferred to an annealing furnace at $475^{\circ} \mathrm{C}$, i.e., the glass transition temperature of the glass, and was annealed for $0.5 \mathrm{~h}$ before the furnace was turned off.

\subsection{Sample preparation}

The obtained glass blocks were cut to pieces with a size of about $2 \times 2 \mathrm{~cm}^{2}$ with diamond coated blade using a Sectocom machine (Struers, Denmark). After cutting the samples were ground coparallel on a cast iron disk using water suspended $\mathrm{SiC}$ powder with ISO/FEPA grit size of $80,220,400,800$ and 1200 . The samples were polished on an MD Plan cloth (Struers, Denmark) with $9 \mu \mathrm{m}$ diamond paste and further polished on another MD Plan cloth with $3 \mu \mathrm{m} \mathrm{CeO}$ powder humidified with water. After grinding and polishing, the samples had a thickness of 3-4 mm. From each melt, three glass pieces were prepared, which represent $15-20 \mathrm{wt} . \%$ of the glass melt.

\section{Table 1}

The homogenisation conditions of the studied glass melts, including the retention ( $R$ ) and stirring (S) durations at $1120{ }^{\circ} \mathrm{C}$. SR series refers to the glass series that underwent stirring followed by retention, whereas RS series refers to retention followed by stirring. For both series, the total homogenisation duration is fixed at $15 \mathrm{~min}$. The number behind both SR and RS refers to the stirring duration.

\begin{tabular}{llllll}
\hline SR series & SR2 & SR4 & SR6: & SR10: & SR15: \\
$(\mathrm{S}+\mathrm{R})(\mathrm{min})$ & $2+13$ & $4+11$ & $6+9$ & $10+5$ & $15+0$ \\
RS series & RS4: & RS6: & RS9: & RS12: & RS15: \\
$\quad(\mathrm{S}+\mathrm{R})(\min )$ & $11+4$ & $9+6$ & $6+9$ & $3+12$ & $0+15$ \\
\hline
\end{tabular}

\subsection{Striae characterisation}

The striae were analysed by means of image analysis, which is an effective method to characterise striae in various glasses [9]. The image acquisition was performed by an Epson Perfection V700 Photo scanner (Seiko Epson Corporation, Nagano, Japan) working in transmission mode at 8 bit, and at a brightness of -15 and a contrast of 40 . Some of the glasses contain bubbles. Since the bubbles affect the stria characterisation, they were removed from the acquired image through image processing prior to the striae characterisation in the programme Image [20] as described in details elsewhere [21]. The transmission of the sample was converted to a grey value on the acquired image during the image acquisition. The grey values of the image were recorded along an inserted line (line scan) in the image with a length of 2000 pixels, which at the applied resolution of 3200 DPI corresponds to $15.88 \mathrm{~mm}$. The recorded grey values were converted into absolute transmissions by means of a transmission calibration standard (IT8, T070408, LaserSoft Imaging). To remove the effect of sample thickness on the stria characterisation, the transmission values were normalised to a constant sample thickness by applying the Lambert-Beer law. Thus the difference in transmission values reflects the change of the absorption of the sample caused by $\mathrm{CoO}$. In the Lambert-Beer law, the extinction coefficient was set to unity. It is reasonable to assume a fixed extinction coefficient since only the concentration of $\mathrm{CoO}$ varies and concentration differences in $\mathrm{CoO}$ are rather small (maximum $0.4 \mathrm{wt} . \%$ ). Therefore, it is possible to convert the grey values of the image into a relative stria concentration through the Lambert-Beer law. 500 lines scans were recorded from the sample and a blank foil and processed according to a method reported elsewhere [9].

\section{Results}

To explore the effect of stirring on striae in glass melts, we first perform simulation of stria formation and deformation of the striae through stirring. The image with the simulated striation shows a periodic structure due to a fixed stria length of 200 pixels (Fig. 1A). Through processing of the image with the striation, it is possible to simulate a stirring effect. The striation subjected to 1,2 or 3 times stirring of $360^{\circ}$ is shown in Fig. 1B-D. Upon stirring, a deformation of the stria occurs, implying that the stirred striation has lost the periodicity of the initial striation. The corners of the image are almost unaffected by the stirring, suggesting that these domains in a real glass melting furnace would be dead-zones under the applied stirring conditions. To quantify the apparent shift in stria dimension due to stirring, the grey value across the images in Fig. 1 is measured. For images of real samples, the grey value is a quantity that is proportional to the optical transmission of the glass and therefore, measurement of the grey value of images can be regarded as a transmission measurement. To study the grey value fluctuations on the images, a line scan is performed. During the line scan, the grey value of the image is recorded along an inserted line with a length of 2000 pixels. The length of the fluctuations in grey value is quantified by subjecting the line scan to Fourier transformation [19]. The Fourier transformation spectra of line scans on each of the four images in Fig. 1 are shown in Fig. 2. The unstirred striation (Fig. 1a) shows a sharp peak at 200 pixels identical to the stria size of the striation. After being subjected to one round of stirring (dark grey curve), the sharp peak at 200 pixels vanishes and instead multiple peaks at dimensions down to 30 pixels are observed (Fig. 2). Further stirring (grey and light grey curves) generates striae with dimensions below 30 pixels. From the four Fourier transformation curves it can be stated that stirring deforms the striations and this leads to the generation of both larger and smaller striae, i.e., to a broadening of the size distribution of striae. The area under the curve in the Fourier transformation spectra, which is a measure of the total stria content, is unaffected by the stirring. 


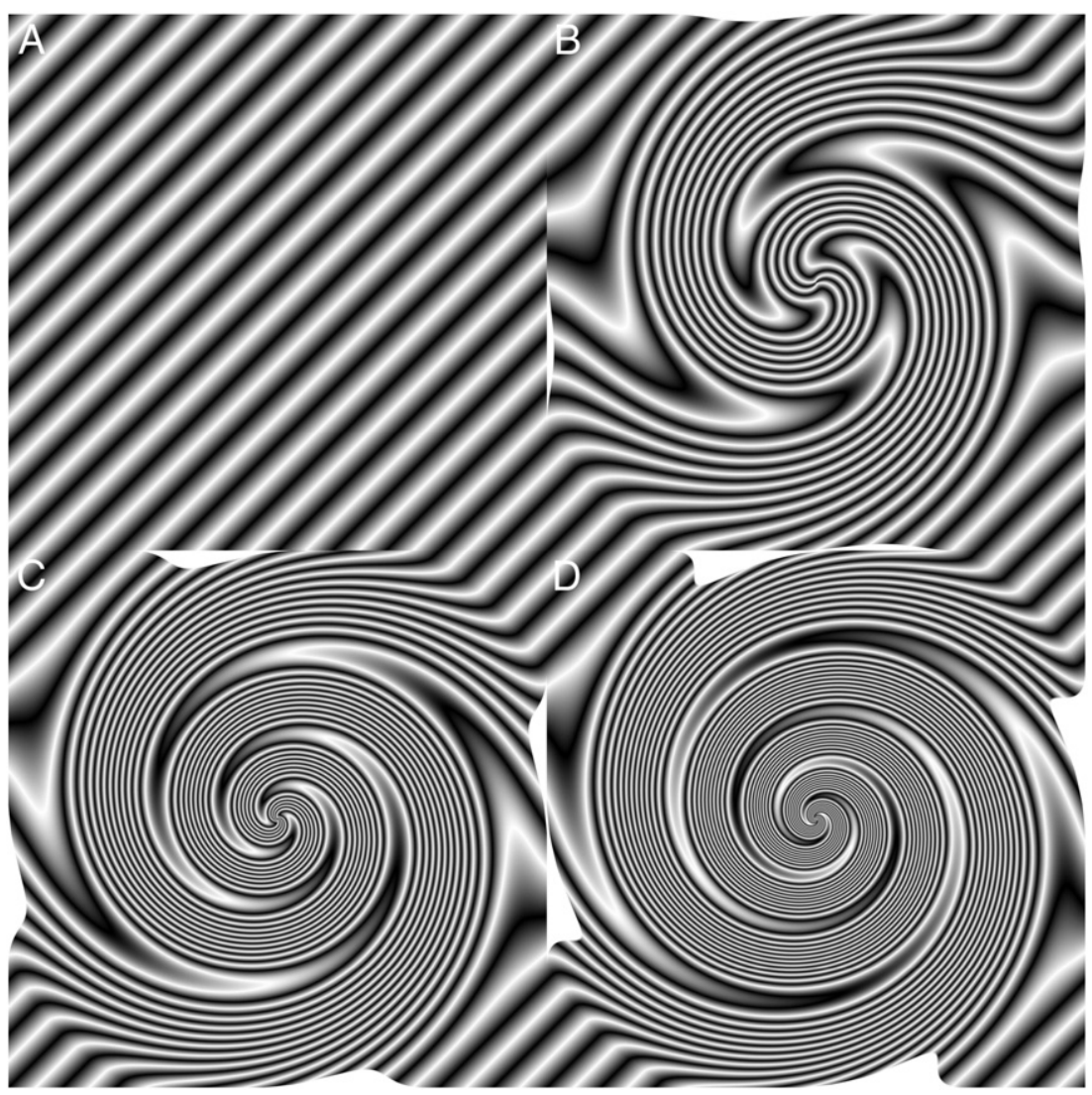

Fig. 1. Images of a simulated striation (A) and the same striation subjected to stirring through image processing (B-D). The simulated striation has a stria length of 200 pixels. The simulated striation was subjected to 1,2 , or 3 times $360^{\circ}$ stirring in images $\mathrm{B}, \mathrm{C}$, and $\mathrm{D}$, respectively.

To explore whether the observations from the stirring simulations are valid, different degrees of stirring are carried out on the borosilicate melts. To obtain striations in the melt, grains of a $\mathrm{CoO}$ doped glass are added into a colourless homogenous batch of the borosilicate glass with the same chemical composition. As expected, blue $\mathrm{CoO}$ enriched striations are obtained in the melt and the striations can weakly be observed through visual inspection of the resulting glass. During the melting process, the size of the striations and the concentration difference of $\mathrm{CoO}$ between the striated domains and the surrounding melt diminish, which is a process referred to as stria equilibration. The equilibration rate of the striae is investigated by maintaining a fixed duration between the time point for addition of the $\mathrm{CoO}$ doped glass to the initially prepared glass melt and that for melt casting. The extent of the striae in the glasses is determined through line scans, which undergo Fourier transformation. The

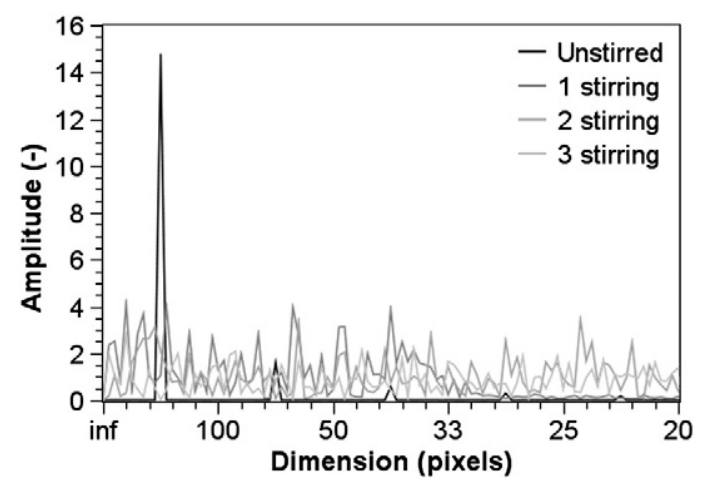

Fig. 2. Fourier transformation spectra of a simulated periodic striation with a stria length of 200 pixels and the same striae subjected to 1,2 or 3 times $360^{\circ}$ stirring. integrated Fourier transformation spectra of two glasses from the SR and one glass from the RS series are shown as examples in Fig. 3. Prolonging the stirring period leads to a lower integral intensity, i.e., smaller optical transmission fluctuations in the glass and consequently, lower compositional difference to the glass matrix. A lower integral intensity implies an improved homogeneity. Since the integral intensity displays the largest increase at dimensions above $100 \mu \mathrm{m}$, it can be inferred that large striae dominate the striation degree of glasses. This statement can be substantiated by the fact that the $\mathrm{CoO}$ doped glass pieces have a size of $1-2 \mathrm{~mm}$. The images of the glasses are acquired at a resolution of 3200 DPI (dots per inch), i.e., one pixel on the acquired images corresponds to $8 \mu \mathrm{m}$. A fluctuation in

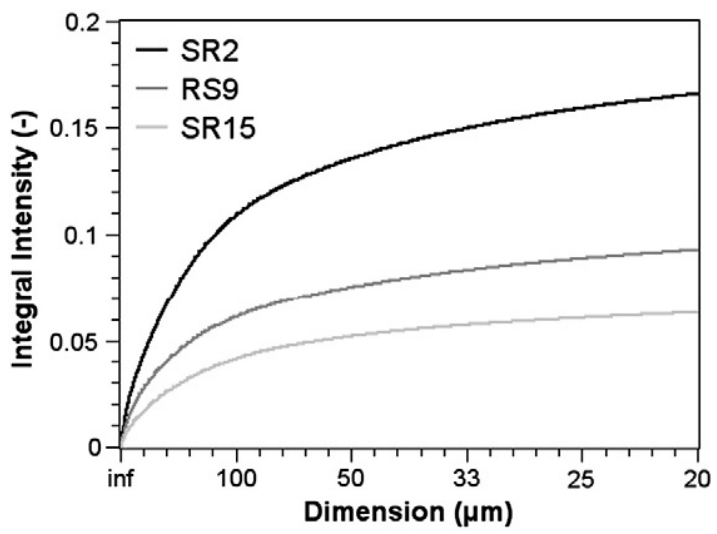

Fig. 3. Integral intensity (amplitude of the Fourier transformation integrated from large to small stria dimensions) against stria dimension for two glasses from the SR series (stirring followed by retention) and one glass from the RS series (retention followed by stirring). 
optical transmission requires at least 2 pixels, i.e., only fluctuations with a size above $16 \mu \mathrm{m}$ can be detected with the applied image acquisition technique. Therefore, the integral intensity at $20 \mu \mathrm{m}\left(I_{20}\right)$ is used as a measure of the total stria content in the glasses. As expected from the curves in Fig. 3, the total integral intensity $\left(I_{20}\right)$ decreases with increasing stirring duration (Fig. 4). The integral intensity shows an inversely s-shaped trend, implying that for the short and the long time stirring experiments, the melt homogeneity increases slightly with stirring duration, whereas for the medium time stirring, the homogeneity increases more sharply. Compared to a non-stirred melt (dashed line in Fig. 4), the total integral intensity is reduced by $63 \%$ when the melt is stirred during the entire 15 min interval. The SR series (stirring followed by retention) shows a faster homogenisation process compared to the RS series (retention followed by stirring). In other words, the homogenisation rate increases if the stirring is conducted at the beginning of the homogenisation process than at the end of the process. The effect of the time point of the stirring on the homogeneity is determined from the difference between the trend lines of the SR and RS series (Fig. 4 inset). The trend lines are based on the same mechanism describing an inversely s-shaped behaviour. The difference has a maximum around $7.5 \mathrm{~min}$, i.e., at half the interval duration of $15 \mathrm{~min}$.

\section{Discussion}

Through simulations of stria formation and stria deformation, it is possible to discriminate between the stirring and the diffusion effects on the striation since one of both effects can be considered independently during the simulation. For real glass melts, diffusion and stirring simultaneously occur and therefore the interpretation of experimental data is more difficult than simulation. From the simulations it is found that stirring broadens the distribution of the prestirred stria dimensions to both large and small striae (Fig. 2). Stirring does not equilibrate and hence, not eliminate the concentration difference from striae to melt matrix. In contrast, equilibration of striae proceeds through elimination of the gradient in chemical potential that exists between the striated domain and the surrounding melt. During the elimination of the chemical potential gradient, the change of the entropy is more influential than that of the enthalpy. Thus, it can be stated that the elimination of striae proceeds through an entropy driven diffusion of the species (e.g. $\mathrm{Co}^{2+}$ in the present melt) that are enriched or depleted in the striae. Therefore, the effect of stirring on the homogenisation rate originates from the conversion of

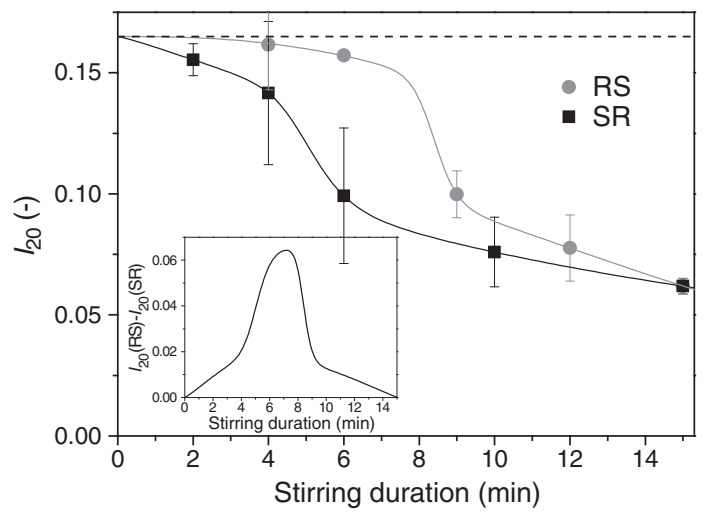

Fig. 4. Integrated intensity $\left(I_{20}\right)$ at a stria size of $20 \mu \mathrm{m}\left(I_{20}\right)$ for both the RS (retention followed by stirring) and the SR (stirring followed by retention) series of glasses as a function of stirring duration at $1120^{\circ} \mathrm{C}$ during the melting process. The dashed line represents the integrated intensity of the glass only subjected to retention for $15 \mathrm{~min}$, while the solid lines are the guide for the eyes to show the trends of the change in the extent of the striation of the glasses with the stirring duration. The empirical trend lines reflect the inversely s-shaped behaviour. The error bar represents the standard deviation of the three samples prepared from each melt. Inset: the difference between the trend lines of the RS and SR series, $I_{20}$ (RS)- $I_{20}$ (SR). large striae into small ones. Complete elimination of a stria occurs when the diffusion length of the i'th species $\left(x_{i}\right)$ is larger than half the stria dimension $(d)$

$x_{\mathrm{i}} \geq 0.5 d$

The factor of 0.5 in Eq. (1) means that the equilibration of the stria begins from both its interfaces to the surrounding glass melt. The diffusion length $x$ is related to the melting duration $(t)$ at the melt temperature through the parabolic equation:

$x_{i}=c_{i} \cdot t^{1 / 2}$

where $c_{i}$ is a component specific constant that depends on chemical composition of the melt and the melt viscosity and thereby the temperature of the melt. Eq. (2) implies that the diffusion length is independent of stirring. The effect of stirring on the homogenisation process is solely attributed to the decrease in stria dimension (Eq. (1)). The conversion of striae to small dimensions during stirring makes an increasing number of striae fulfil the diffusion condition given by Eq. (1). Consequently, the stria equilibration rate in the melt is enhanced.

The melting experiments have been conducted at the same melting temperature and melting duration, i.e., the diffusion length $x$ is similar for all samples. Furthermore, since blue glass grains with a size of 1$2 \mathrm{~mm}$ are added to obtain striae in the melts, $d$ is initially $1-2 \mathrm{~mm}$ for all melts. Since only $\mathrm{CoO}$ causes the striae in the melts, $c_{\mathrm{i}}$ remains unchanged during the experiments. This implies that all terms in Eqs. (1) and (2) except $d$ are constant during the experiments. The starting value of $d$ is the same for all the experiments, but is altered to a varying extent due to the variations in the stirring conditions.

During the $15 \mathrm{~min}$ interval, a net effect of stirring of $63 \%$ is obtained (Fig. 4). Remarkably, the effect is obtained without changing the diffusion length $(x)$ in the melt as the melt temperature, the melt composition and the melting duration are fixed. Thus, this net effect can only be attributed to the creation of small striae by stirring that are faster to equilibrate than the larger ones due to their small size. After equilibration of the small striae, the stirring ensures that the remaining large striae are converted to smaller ones that can be equilibrated within the time frame of the experiment. In other words, the conversion of large striae into smaller ones is a continuous process that takes place during stirring of a striated glass melt. For stirring durations shorter than $15 \mathrm{~min}$, the homogenisation enhancement due to stirring depends on whether the stirring is applied at the beginning or at the end of the homogenisation period. This difference is the effect of stirring and the difference is quantified in the inset in Fig. 4. The difference in homogeneity between the SR and RS series increases up to a stirring duration of $7.5 \mathrm{~min}$. In the SR series where stirring is applied at the beginning of the homogenisation period, the large striae are initially converted to smaller ones, which can be equilibrated by diffusion within the time frame of the experiment. In the RS series, stirring occurs at the end of the homogenisation period, which implies that prior to the stirring only large striae that have a long equilibration time are present in the melt. In other words, the initial retention period in the RS series has a minor impact on the stria equilibration as only large striae are present. Due to the deformation of striae, $I_{20}$ shows a faster decrease with the stirring duration for the SR series than for the RS series and therefore the homogeneity difference between the two series increases up to a stirring duration of $7.5 \mathrm{~min}$. For stirring durations longer than $7.5 \mathrm{~min}$, the homogeneity difference between the two series diminishes. As the stirring duration increases, the initial retention period in the RS series decreases and therefore a smaller fraction of the 15 min period occurs mainly with the presence of large striae. Therefore, for longer stirring durations, the conditions of the SR and RS series approach each other and consequently the difference in homogeneity between the two series gradually diminishes. 
The effect of stirring becomes smaller with extending the stirring duration, and this is seen from the decrease of the slope of the trend lines in Fig. 4 with increasing the stirring duration. However, from a comparison of the glasses stirred for 2 and $4 \mathrm{~min}$ (SR2 and SR4), short stirring durations are insufficient to deform the striae and therefore melts stirred for short durations are only slightly more homogeneous than unstirred melts. According to the simulation study described above, a certain degree of stirring is required to convert the large striae into smaller ones. The agreement between the simulations and the experiments indicates that if a melt is cast immediately after stirring, it contains small striae.

\section{Conclusions}

The physical origin of the effect of stirring on the homogenisation rate in glass melts is revealed through simulations and experiments on a borosilicate glass melt subjected to various degrees of mechanical stirring. Stirring deforms the striae in the melt and this broadens the size distribution of the striae by creating both larger and smaller striae in the glass melt. The total stria volume and the compositional difference between the stria and the matrix are not affected by stirring in itself. The elimination of striae proceeds through diffusion and not through stirring. Each melting temperature and duration corresponds to a certain diffusion length. Since stirring converts larger striae to smaller ones, the number of striae with a size below the diffusion length increases and therefore, stirring enhances the homogenisation rate of melts.

\section{Acknowledgements}

We thank A P. Brønnum, B. H. Hede, H. Lundø, L. S. Trankjær, M. Jensen, R. E. Gissel and S. S. Damkjær for experimental assistance. R.
Keding and M. Solvang are acknowledged for useful discussions. This work is financially supported by Rockwool International A/S.

\section{References}

1] R.G.C. Beerkens, J. van der Schaaf, J. Am. Ceram. Soc. 89 (2006) 24

[2] M.D. Lund, Y.Z. Yue, J. Jpn. Ceram. Soc. 116 (2008) 841.

[3] K. Bange, H. Müller, C. Strubel, Microchim. Acta 132 (2000) 493.

[4] R.G.C. Beerkens, J. Am. Ceram. Soc. 86 (2003) 1893

[5] M.H. Chopinet, Glass Technol.: Eur. J. Glass Sci. Technol. A 50 (2009) 117.

[6] L. Grund, B. Jonson, Glass Technol.: Eur. J. Glass Sci. Technol. A 50 (2009) 62.

[7] L. Grund, B. Jonson, K. Lundstedt, Glass Technol.: Eur. J. Glass Sci. Technol. A 50 (2009) 241.

[8] V. Tonarova, L. Němec, M. Jebavá, Glass Technol.: Eur. J. Glass Sci. Technol. A 51 (2010) 165.

[9] M. Jensen, L. Zhang, R. Keding, Y.Z. Yue, Int. J. Appl. Glass Sci. 2 (2011) 137.

[10] M. Jensen, R. Keding, Y.Z. Yue, Glass Technol.: Eur. J. Glass Sci. Technol. A 52 (2011) 127

[11] P. Hrma, MJ. Schweiger C.J. Humrickhouse, J.A. Moody, R.M. Tate, T.T. Rainsdon, N.E. Tegrotenhuis, B.M. Arrigoni, J. Marcial, C.P. Rodriguez, B.H. Tincher, Ceramics-Silikaty 54 (2010) 193.

[12] M.H. Chopinet, E. Gouillart, S. Papin, M.J. Toplis, Glass Technol.: Eur. J. Glass. Sci. Technol. A 51 (2010) 116

[13] S. Lin, C. Ionescu, S. Baker, M.E. Smith, J.R. Jones, J. Sol-gel Sci. Technol. 53 (2010) 255.

[14] A.R. Cooper, Glass Technol. 7 (1966) 2.

[15] S.S. Wang, M. Cable, J. Non-Cryst. Solids 80 (1986) 642

[16] M. Cable, J. Am. Ceram. Soc. 81 (1998) 1083.

[17] D. Hulsenberg, B. Halbedel, G. Conrad, A. Thess, Y. Kolesnikov, U. Ludtke, Glass Sci. Technol. 77 (2004) 186

[18] U. Krieger, B. Halbedel, D. Hülsenberg, A. Thess, Glass. Technol.: Eur. J. Glass. Sci. Technol. A 49 (2008) 33.

[19] M. Jensen, R. Keding, Y.Z. Yue, J. Am. Ceram. Soc. 93 (2010) 2705.

[20] M.D. Abramoff, P.J. Magelhaes, S.J. Ram, Biophotonics Int. 11 (2004) 36

[21] M. Jensen, R. Keding, H.H. Poschwatta, S. Fjendbo, Y.Z. Yue, Glass Technol.: Eur. J. Glass Sci. Technol. A 51 (2010) 147. 